\title{
Transmission line fault location: Simulation of real faults using wavelet transform based travelling wave methods
}

\author{
Mustafa Akdag a*, Sabir Rustemli a \\ a Bitlis Eren University, Department of Electrical an Electronics Engineering, TR-13000, Bitlis Turkey
}

\section{ART ICLE INFO}

Article history:

Received 30 November 2019

Received in revised form 12 December 2019

Accepted 12 December 2019

\section{Keywords:}

Fault Location

Transmission line

Travelling Wave

Wavelet Transform

\begin{abstract}
A B S T R A C T
In this study, High Voltage Transmission Line fault location accuracy of distance relays running impedance algorithm are compared with Travelling Wave (TW) method. Line faults in $154 \mathrm{kV}$ Tatvan Muş and 154 kV Patnos-Erciş lines in Turkish Electrical Transmission System are analyzed. Real faults in both lines are simulated in MATLAB-SIMULINK. Tower configuration and conductor properties of the lines and the source impedances are included in the simulation to comply with real system. Simulations show that both single-end and double-end Wavelet Transform (WT) based TW methods have better accuracy then the distance relays computing fault location by impedance methods.
\end{abstract}

(C) 2019. Turkish Journal Park Academic. All rights reserved.

\section{Introduction}

Locating fault in Transmission Lines is vital for reliable, sustainable and efficient delivery of electrical energy. Faults occurred in Transmission lines may cause long power outages. Fault location accuracy in transmission lines affect the consumed time for clearing the fault by maintenance crew. The accuracy in impedance based methods is limited by factors like fault resistance, load flow and compensated lines etc. An example of $\pm 1 \%$ error in fault location for a $500 \mathrm{~km}$ line means the maintenance crew have to search the fault within $5 \mathrm{~km}$ span of the line. This means approximately 30 towers. Percentage error for determining fault location in $\mathrm{HV}$ transmission lines can be calculated by using (1).

$\%$ Error $=\left|\frac{(\text { Actual Location }- \text { Computed Location })}{\text { Total Line length }}\right| \cdot 100$

Common fault location methods can be categorized as Impedance-Based Methods [1] and Travelling Wave(TW)Based Methods [2]. Also fault location methods can be classified as single-end and double-end [3]. Single-End Methods use data from single end of the line. Double-End Method use data from both side of the line. For this reason,
Double-End Methods need time synchronization of both end data. Time synchronization established by means of GPS modules. Impedance-based methods have lower accuracy and less cost compared to TW-based ones. Single-End Methods have lower accuracy and less cost compared to double-end ones. TW-Based Methods need supplemental logic to classify fault type and locate fault for all fault types [4].

Discontinues like faults, lightning strikes, opening or closing the circuit breaker etc. causes high-frequency $(10 \mathrm{kHz}$ to $600 \mathrm{kHz}$ ) voltage and current transients moving towards both ends of the line [5]. These transients are called Traveling Waves (TW). TWs propagate along the line with the velocity near the speed of light, $300.000 \mathrm{~km} / \mathrm{s}$.

TW propagation initiate at the same time with the discontinuity. This first wave is called incident TW. At every discontinuity point, that is a high impedance point wave is divided three parts: some reflected back, some is transmitted through the point and some is absorbed by the point. In the case of transmission line fault, busbars at each side of the line and fault point are discontinuities (Figure 1).

\footnotetext{
* Corresponding author. 


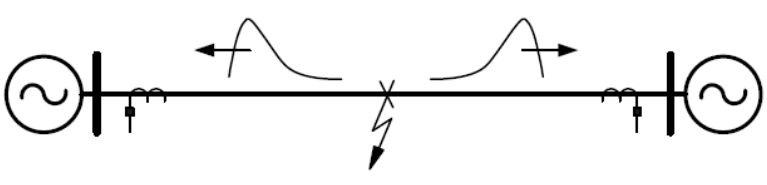

Figure 1. Travelling Waves in case of transmission line fault

For Double-End TW Method, arrival times of incident TWs to each side of the line are extracted from overall fault (current or voltage) signals. For Single-End TW Methods, arrival times of incident TW and first reflected TW at one side of the line are extracted from overall fault (current or voltage) signal. Extraction of these arrival times are made by means of signal processing methods like wavelet transform [6], deviation method [7] or transient spectrum methods [8]-[11]. Difference of these extracted times of each method is used in calculation of fault location. Figure 2 shows how travelling waves be formed due to a fault occurred in the line, also called Bewley's lattice diagram [12].

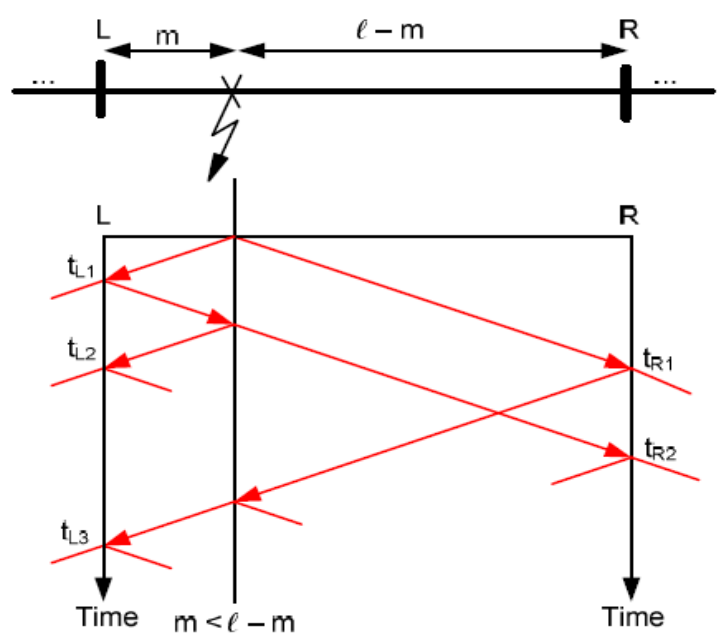

Figure 2. Bewley's lattice diagram showing incident TWs.

This study determines transmission line fault location with both Single-End and Double-End TW Fault Location Method using wavelet transform by means of simulating real faults occurred in the transmission line in MATLAB-SIMULINK.

\section{Materials and Methods}

\subsection{Single-End TW Fault Location Method}

A fault occurred in the point $\mathrm{m}$, in Figure 2, causes TW moving towards both ends of the line. $L$ and $R$ are line ends. $t_{L i}$ and $t_{R i}$ are successive reflection times of the TWs reaching corresponding end of the line. Fault location can be calculated by using arrival times of indecent TW and the first reflected TW at the same side of the line. Fault location calculated by:

$m=\left(\frac{t_{L 2}-t_{L 1}}{2}\right) \cdot v$

and

$v=\frac{1}{\sqrt{L \cdot C}}$

where: $m$ : fault point $(\mathrm{km})$

$t_{L 2}, t_{L 1}:$ arrival times of first reflected and incident TW respectively (s)

$v$ : velocity of TW propagation $(\mathrm{km} / \mathrm{s})$

$L$ : Unit line inductance $(\mathrm{H} / \mathrm{km})$

$C:$ Unit line capacitance $(\mathrm{F} / \mathrm{km})$

\subsection{Double-End TW Fault Location Method}

A fault occurred in the point m, in Figure 2, causes TWs moving towards both ends of the line. $L$ and $R$ are line ends. $t_{L 1}$ and $t_{R 1}$ are incident times of the TWs reaching corresponding end of the line. Fault location can be computed by using arrival times of indecent TWs to both side of the line. Fault location calculated by:

$m=\frac{1}{2} \cdot\left[\ell+\left(t_{L 1}-t_{R 1}\right) \cdot v\right]$

where: $\ell$ : line length

$m$ : fault point $(\mathrm{km})$

$t_{L 1}, t_{R 1}$ : arrival times of Incident TWs respectively (s)

$v$ : velocity of TW propagation $(\mathrm{km} / \mathrm{s})$

\subsection{Case Studies}

\subsubsection{The Fault in 154 kV Patnos-Erciş Line}

Real fault data taken from Line Distance Protection Relay at Patnos Substation for $154 \mathrm{kV}$ Patnos-Ercis Line is considered. The fault is modelled in MATLAB-SIMILINK to apply the SingleEnd TW Method. Phase B to Ground fault (B-G) occurred in December 2, 2016 is examined. Line length is $46,587 \mathrm{~km}$ and fully transposed. First $5,281 \mathrm{~km}$ is double circuit with $795 \mathrm{MCM}$ DRAKE conductor and the rest is single circuit with $477 \mathrm{MCM}$ HAWK conductor. Fault occurred at 7,31 km from Patnos. The cause was the broken insulator (Figure 3). SEL 421 Distance Relay, is used for line protection in Patnos Substation. The Relay computed distance for the fault as $5,38 \mathrm{~km}$. The output of the relay is given in Figure 4.

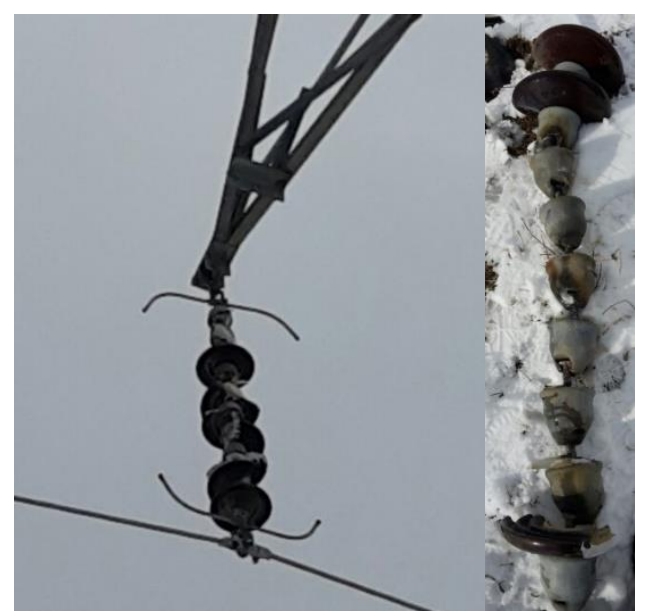

Figure 3. The Fault in $154 \mathrm{kV}$ Patnos-Erciş Line 


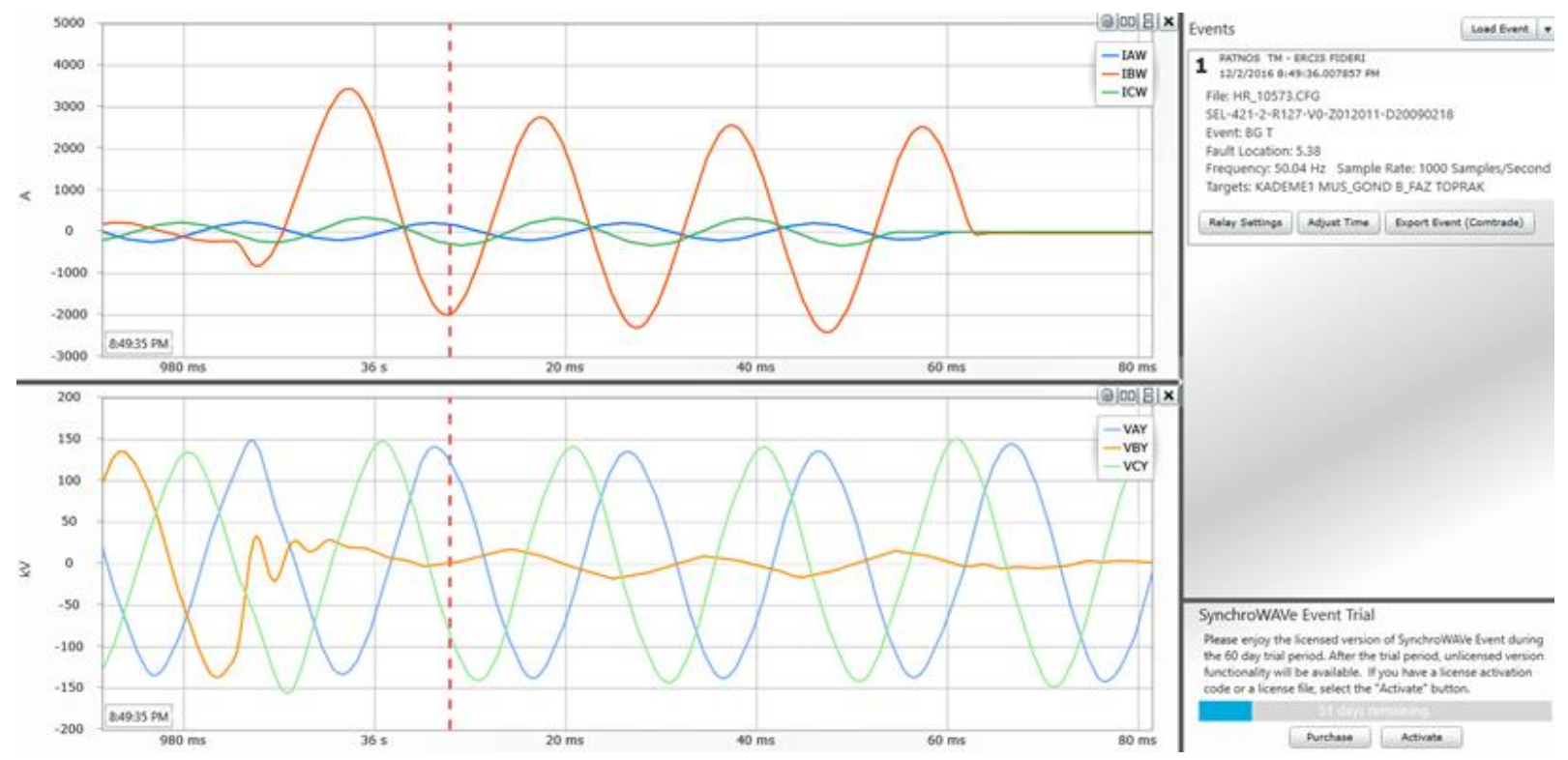

Figure 4. Relay Output for the Fault in $154 \mathrm{kV}$ Patnos-Erciş Line

\subsubsection{The Fault in 154 kV Tatvan-Muş Line}

Real fault data taken from Line Distance Protection Relays at the both side of $154 \mathrm{kV}$ Tatvan-Muş Line is considered. The fault is modelled in MATLAB-SIMILINK to apply the DoubleEnd TW Method. Phase $C$ to Ground fault (C-G) occurred in March 3, 2017 is examined. Line length is 71,3357 km and fully transposed. The line is single circuit with 477 MCM HAWK conductor. Fault occurred at 9,8157 km from Muș. Stork nest caused short circuit between Phase $\mathrm{C}$ and the Tower (Figure 5). Distance Relay at Tatvan Substation gave the fault distance as 62,65 km. Distance Relay at Muş Substation gave the fault distance $10,15 \mathrm{~km}$.

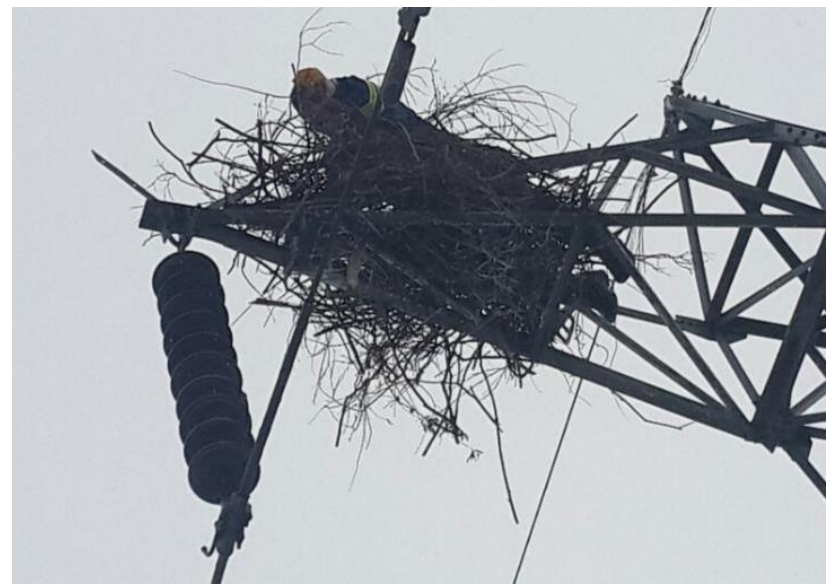

Figure 5. The Fault in $154 \mathrm{kV}$ Tatvan-Muş Line

\subsection{Line Parameters}

Line parameters are obtained by using 'Powergui Compute RLC Line Parameters Tool' (MATLAB), conductor type and measurements of the tower type. Ground resistivity is neglected. $154 \mathrm{kV}$ Patnos-Erciş Transmission Line parameters are given in Table 1 and 154 kV Tatvan-Muș Transmission Line parameters are given in Table 2.

Table 1. $154 \mathrm{kV}$ Patnos-Erciş Transmission Line parameters

\begin{tabular}{cccccc}
\hline \multicolumn{3}{c}{ Single Circuit Section } & \multicolumn{3}{c}{ Double Circuit Section } \\
\hline \multirow{2}{*}{ Parameter } & $\begin{array}{c}\text { Positive } \\
\text { Seq. }\end{array}$ & Zero Seq. & $\begin{array}{c}\text { Positive } \\
\text { Seq. }\end{array}$ & Zero Seq. & $\begin{array}{c}\text { Zero Seq. } \\
\text { Mutual }\end{array}$ \\
\hline $\mathrm{R}$ & 0.12046 & 0.14231 & 0.71534 & 0.8777 & 0.16236 \\
$(\mathrm{Ohms} / \mathrm{km})$ & & & & & \\
$\mathrm{L}(\mathrm{H} / \mathrm{km})$ & 0.0013977 & 0.0022224 & 0.0012629 & 0.0038516 & 0.0022446 \\
$\mathrm{C}(\mathrm{F} / \mathrm{km})$ & $8.5138 \mathrm{e}-$ & $6.1677 \mathrm{e}-$ & $9.4507 \mathrm{e}-$ & & \\
& 09 & 09 & 09 & & \\
\hline
\end{tabular}

Table 2. 154 kV Tatvan-Muş Transmission Line parameters

\begin{tabular}{ccc}
\hline Parameter & Positive Seq. & Zero Seq. \\
\hline $\mathrm{R}(\mathrm{Ohms} / \mathrm{km})$ & 0.12046 & 0.14231 \\
$\mathrm{~L}(\mathrm{H} / \mathrm{km})$ & 0.0013977 & 0.0022224 \\
$\mathrm{C}(\mathrm{F} / \mathrm{km})$ & $8.5138 \mathrm{e}-09$ & $6.1677 \mathrm{e}-09$ \\
\hline
\end{tabular}

\subsection{MATLAB-SIMULINK Simulation of Faults}

\subsubsection{MATLAB-SIMULINK Simulation of the Fault in 154 kV Patnos-Erciș Line}

The simulation is created in MATLAB- SIMILINK using Simscape Power Systems Tool. The simulation is shown in Figure 6. 


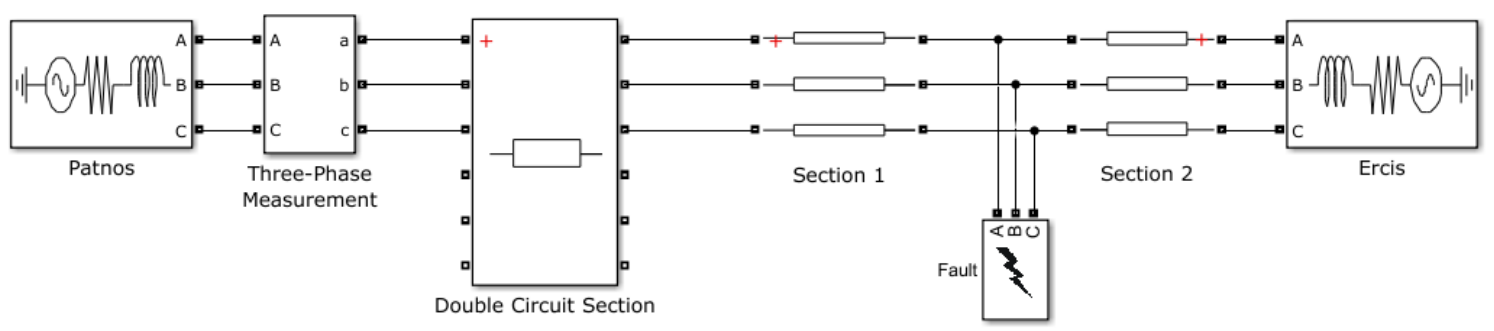

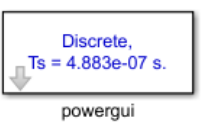

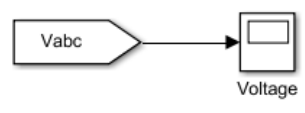

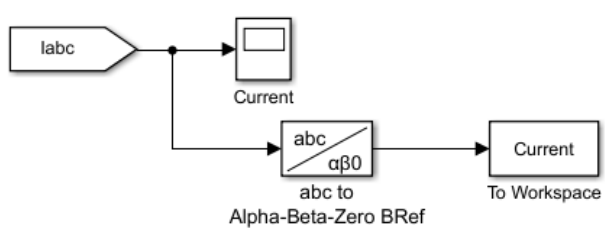

Figure 6. SIMULINK Model of the Fault in $154 \mathrm{kV}$ Patnos-Erciş Line

"Patnos" and "Ercis" sources represent busbars at each side of the line. Source impedance is driven from Three Phase Short Circuit Parameters. The parameters are taken from TEİSS (Turkish Electricity Transmission Corporation). The simulation lasts for $200 \mathrm{~ms}$. The fault is programed from 100 th $\mathrm{ms}$ to 150 th ms. Sampling Rate is $2.048 \mathrm{MHz}$. Fault resistance is chosen as 40 ohms; 20 for arc resistance and 20 for tower resistance and tower footing. Distributed line Model is used. The line divided to sections according to double circuit line section and actual fault location. Base voltage is $154 \mathrm{kV}$ and base power is 100 MVA. In real applications of TW methods

Current Transformer (CT) output is used to compute fault location because of their better frequency responses compared to Capacitance Voltage Transformer (CVT) [13]. That is way current waves are chosen for further computations.

Since we do not need load impedance for the method, the load flow is not involved in the SIMULINK model. The method is independent from load flow and that makes the method more useful compered to impedance based ones. Figure 7 shows simulation output for the fault.

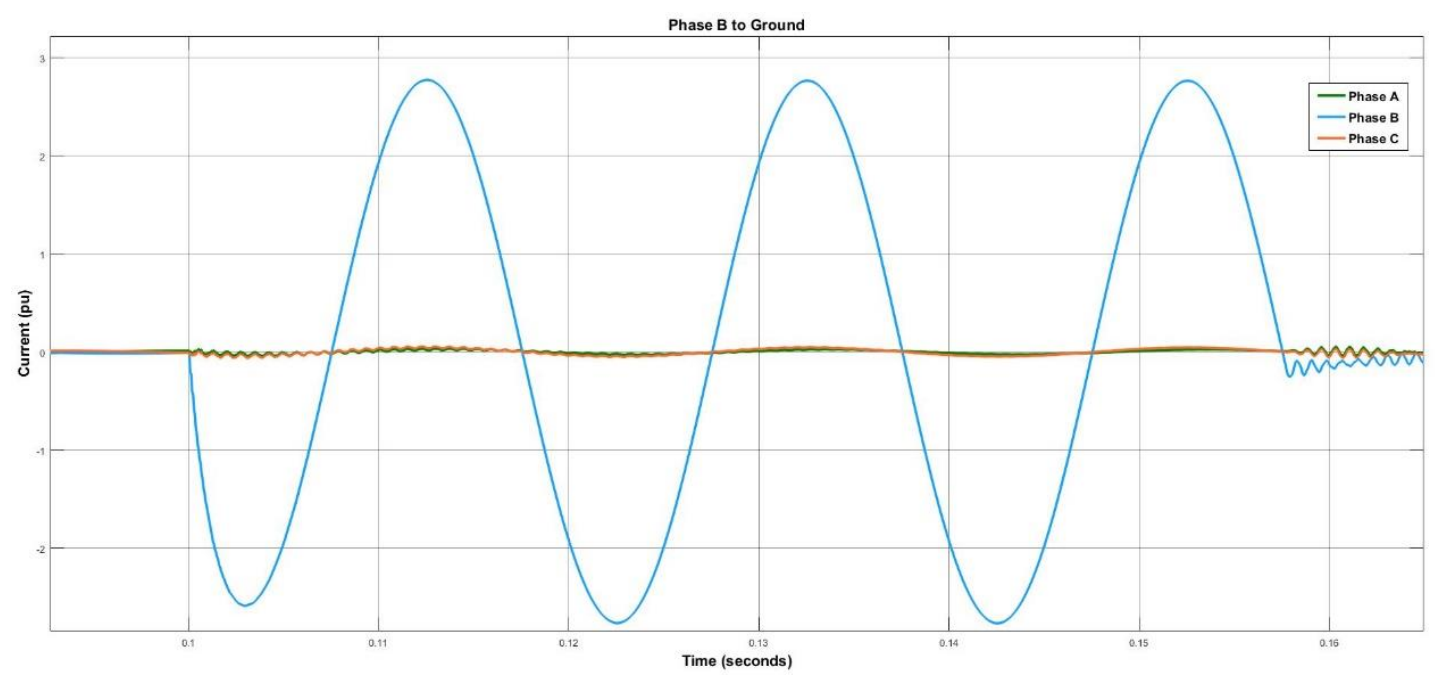

Figure 7. Simulation output for the Fault in $154 \mathrm{kV}$ Patnos-Erciş Line 


\subsubsection{MATLAB-SIMULINK Simulation of the Fault in 154 kV Tatvan-Muş Line}

The simulation is created in MATLAB- SIMILINK using Simscape Power Systems Tool. The simulation is shown in Figure 8.

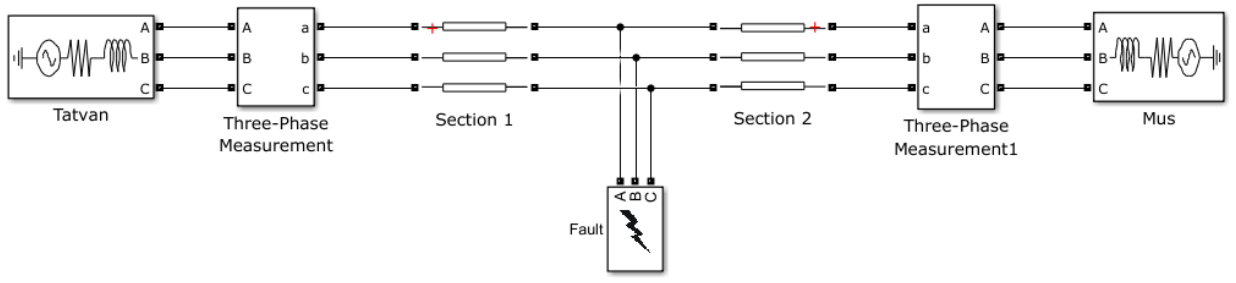

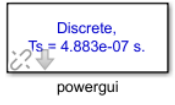
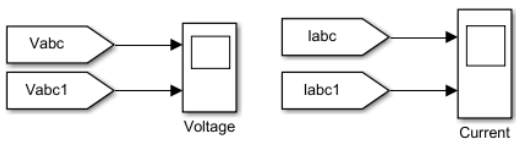

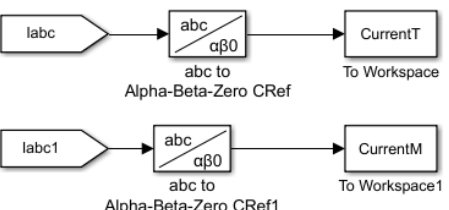

Alpha-Beta-Zero CRef1
Figure 8. SIMULINK Model of the Fault in $154 \mathrm{kV}$ Tatvan-Muş Line

"Tatvan" and "Mus" sources represent busbars at each side of the line. Source impedance is driven from Three Phase Short Circuit Parameters. The parameters are taken from TEİAS (Turkish Electricity Transmission Corporation). The simulation lasts for $200 \mathrm{~ms}$. The fault is programed from 100th $\mathrm{ms}$ to 150 th ms. Sampling Rate is $2.048 \mathrm{MHz}$. Fault resistance is chosen as 40 ohms; 20 for arc resistance and 20 for tower resistance and tower footing. Distributed line Model is used. The line divided to section according to actual fault location. Base voltage is $154 \mathrm{kV}$ and base power is 100 MVA. In real applications of TW methods Current Transformer (CT) output is used to compute fault location because of their better frequency responses compared to Capacitance Voltage Transformer (CVT) [13]. That is way current waves are chosen for further computations.

Since we do not need load impedance for the method, the load flow is not involved in the SIMULINK model. The method is independent from load flow and that makes the method more useful compered to impedance based ones. Figure 9 shows simulation output for the fault.
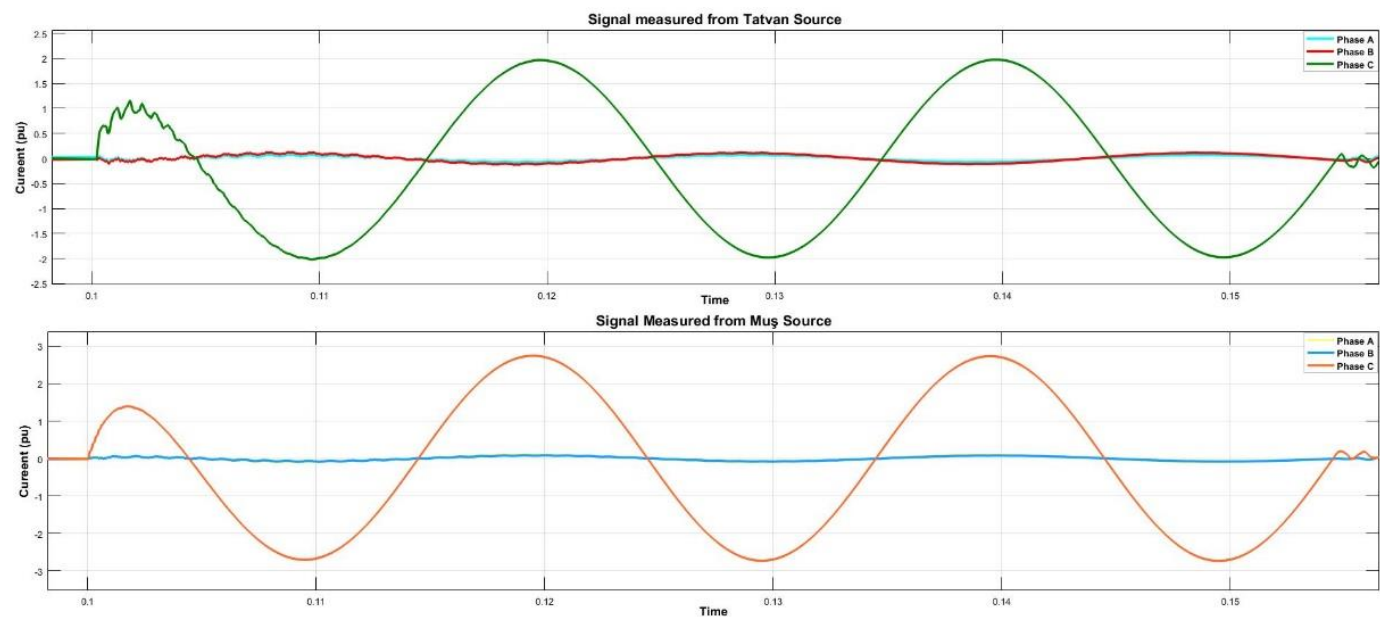

Figure 9. Simulation output for the Fault in 154 kV Tatvan-Muş Line 


\subsection{Modal Transform}

In three phase transmission lines, the travelling waves are coupled and a single wave velocity does not exist. In order to implement methods in three phase systems, the phase domain signals are first decomposed into their modal components using Clarke's Transformation [14]. This transformation is also make simulation more efficient since we do not establish any transposition in models. The Clarke components calculated with reference to Phase A work well for AG and BC faults but will not work optimally for other fault types. In order to cover all fault types, we use three sets of Clarke components with reference to Phase A, Phase B, and Phase C:

$\left[\begin{array}{c}I_{\alpha}^{A} \\ I_{\beta}^{A} \\ I_{o}^{A}\end{array}\right]=\frac{1}{3}\left[\begin{array}{ccc}2 & -1 & -1 \\ 0 & \sqrt{3} & -\sqrt{3} \\ 1 & 1 & 1\end{array}\right]\left[\begin{array}{c}I_{A} \\ I_{B} \\ I_{C}\end{array}\right]$

$\left[\begin{array}{c}I_{\alpha}^{B} \\ I_{\beta}^{B} \\ I_{o}^{B}\end{array}\right]=\frac{1}{3}\left[\begin{array}{ccc}-1 & 2 & -1 \\ -\sqrt{3} & 0 & \sqrt{3} \\ 1 & 1 & 1\end{array}\right]\left[\begin{array}{l}I_{A} \\ I_{B} \\ I_{C}\end{array}\right]$

$\left[\begin{array}{c}I_{\alpha}^{C} \\ I_{\beta}^{C} \\ I_{o}^{C}\end{array}\right]=\frac{1}{3}\left[\begin{array}{ccc}-1 & -1 & 2 \\ \sqrt{3} & -\sqrt{3} & 0 \\ 1 & 1 & 1\end{array}\right]\left[\begin{array}{l}I_{A} \\ I_{B} \\ I_{C}\end{array}\right]$

$\boldsymbol{\alpha}$ and $\boldsymbol{\beta}$ components are called aerial-mode components, $\mathbf{0}$ component is called zero-mode component. $\alpha$-mode of the signal is chosen for further computations. The wave velocity of $154 \mathrm{kV}$ Patnos-Erciş and $154 \mathrm{kV}$ Tatvan-Muş Line can be calculated as in (8).

$v_{\alpha}=\frac{1}{\sqrt{L_{1} \cdot C_{1}}}=\frac{1}{\sqrt{0.0013977 \cdot 8.5138 e-09}}=289888,7059 \mathrm{~km} / \mathrm{s}$

where $L_{1}$ and $C_{1}$ are positive sequence unit inductance $(H / k m)$ and the capacitance $(\mathrm{F} / \mathrm{km})$ of lines respectively.

\subsection{Wavelet Transformation}

In signal processing, Wavelet transform helps to obtain frequency-time resolution of any signal. In other words, it gives us which high frequency component at which time period. Since we know that the TWs in the transmission line has relatively high frequencies of $10 \mathrm{kHz}$ to $600 \mathrm{kHz}$ then the system frequency of $50 \mathrm{~Hz}$ and we need to estimate arrival times of TWs to end of the lines; wavelet can be a proper choice for our application. We use Discrete Wavelet Transform function (dwt) with Daubechies mother wavelet db2 [15]. DWT decomposes original signal into approximation coefficients that is a convolution of the signal with low pass filter and detail coefficients that is a convolution of the signal with high pass filter. The sample number of the signal is lowered by ratio of 2 with each filtering operation. This is called downsampling. Figure 10 shows block diagram of dwt for first level.

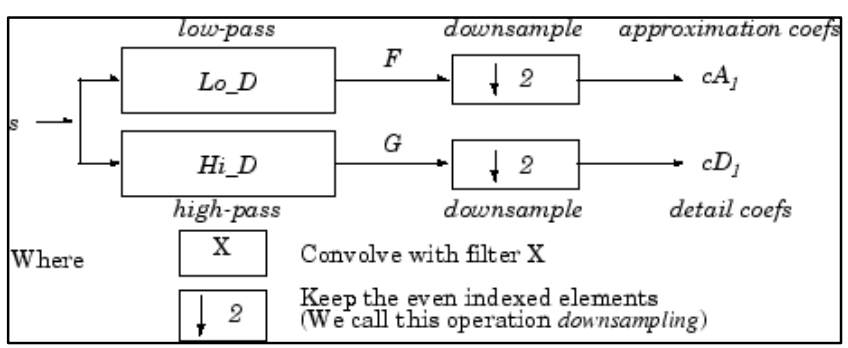

Figure 10. Block diagram of dwt for first level

Mathematical expression for dwt is [16]:

$W_{\psi, s}(m, n)=2^{\frac{-m}{2}} \sum_{k} s(k) \psi\left(k 2^{-m}-n\right)$

Where, ? is dwt, ? is scale parameter, ? is time shift parameter, ? is mother wavelet and ? is the signal.

16384 points of the $\alpha$-mode signal are extracted from overall signals starting just before fault time (100th $\mathrm{ms}$.). This is approximately half period of the current signal. Sampling period is 2,048 MHz. Since 16384 can be written as 2四, where ? is an integer, the signal can be processed for wavelet transform.

Figure 11 shows discrete wavelet transforms of the fault signal measured at Patnos side. First one is $\alpha$-mode of the signal, second is approximation coefficients, and last one is detail coefficients. Observe that the sudden change in the signal can be seen in the detail coefficients with the exact same time. 

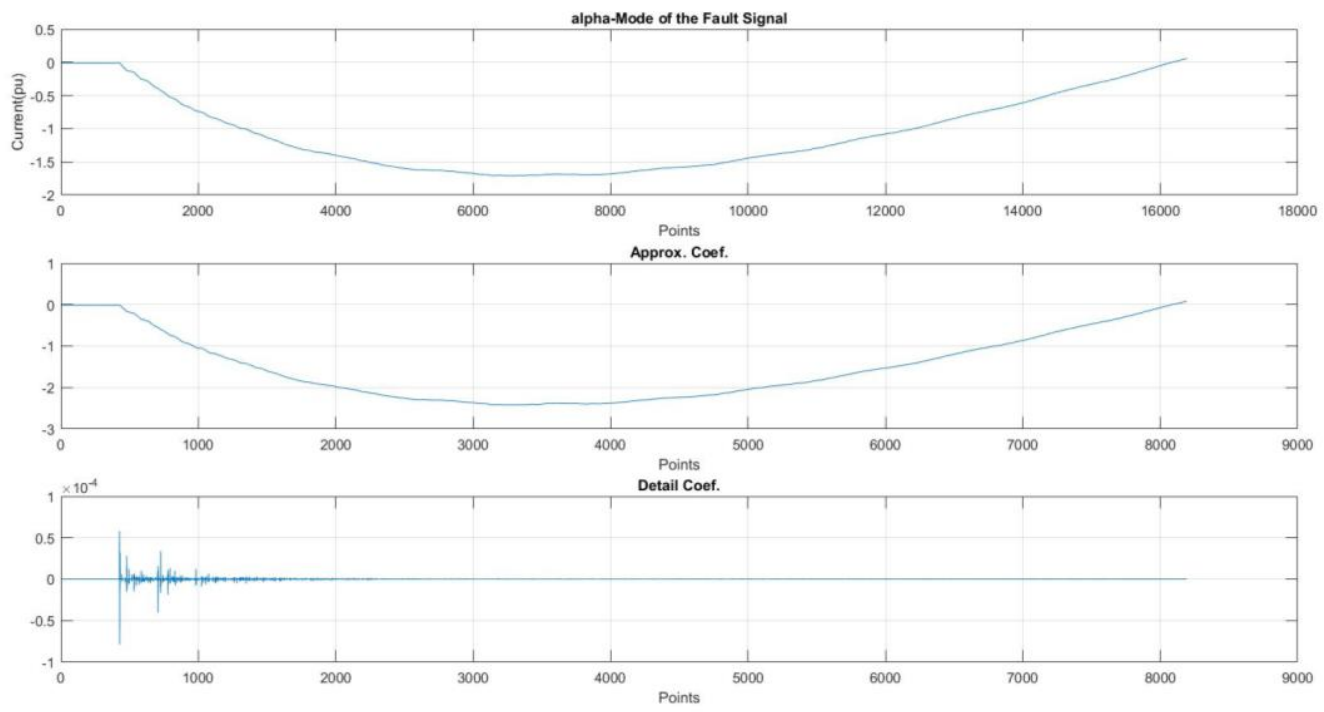

Figure 11. Dwt of the Fault Signal at Patnos Side

Figure 12 and 13 show discrete wavelet transforms of fault signals measured at Muş side and Tatvan side respectively. First one is $\alpha$-mode of the signal, second is approximation coefficients, and last one is detail coefficients. Observe that the sudden change in the signal can be seen in the detail coefficients with the exact same time.
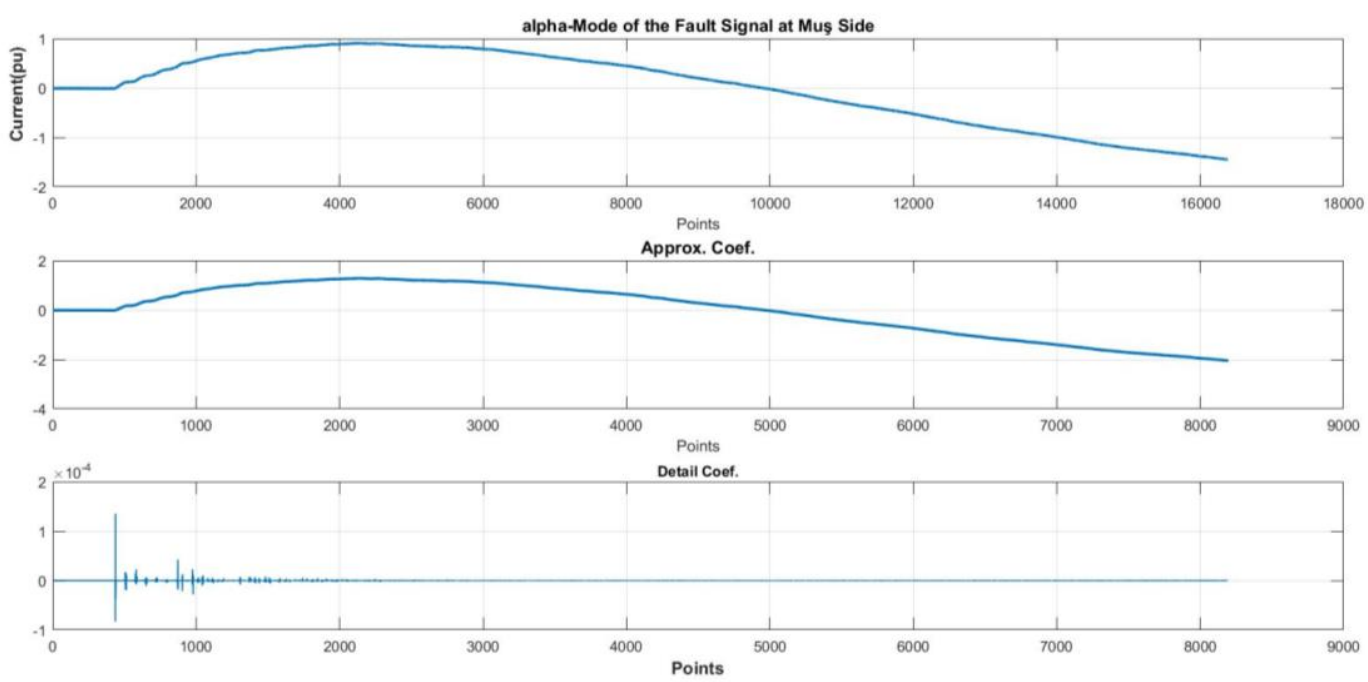

Figure 12. Dwt of the Fault Signal at Muş Side 

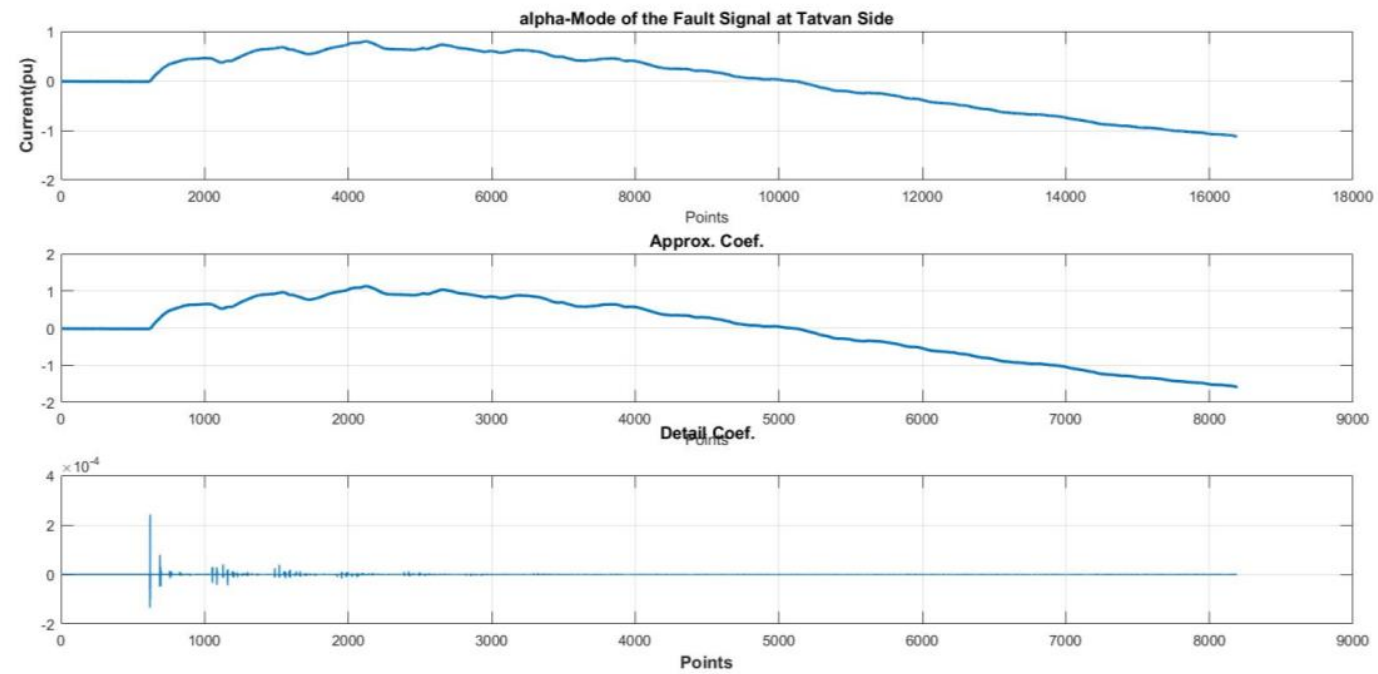

Figure 13. Dwt of the Fault Signal at Tatvan Side

\section{Results}

\subsection{Simulation Results of the Fault in 154 kV Patnos- Erciş Line with Single-End Method}

By wavelet transform the difference of arrival times of incident TW and first reflected TW can be obtained. Peaks in Detail Coefficients of first level DWT represent sudden changes in the signal. The difference of sample number of first peak and second opposite polarity peak gives us the time difference of arrival times of incident TW and first reflected TW. The fault location expression with $\alpha$-mode velocity for downsampled detail coefficients:

$m=\left(p_{2}-p_{1}\right) \cdot \frac{v_{\alpha}}{f_{s}}$

where $m$ is fault location, $p_{1}$ is sample number of first peak with highest amplitude, $p_{2}$ is sample number of second peak with opposite polarity than $p_{1}, v_{\alpha}$ is wave propagation velocity in $\mathrm{km} / \mathrm{s}$ and $f_{s}$ is sampling rate in Hz. Figure 14 shows first peaks with sample numbers at each side.

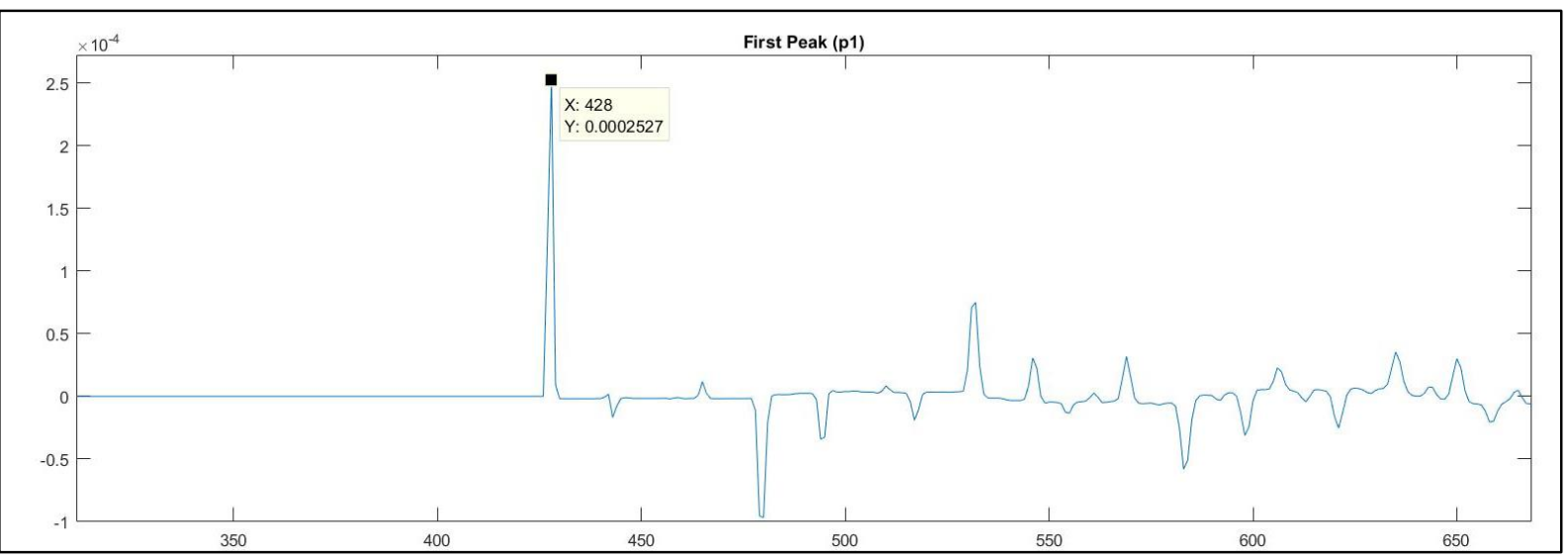




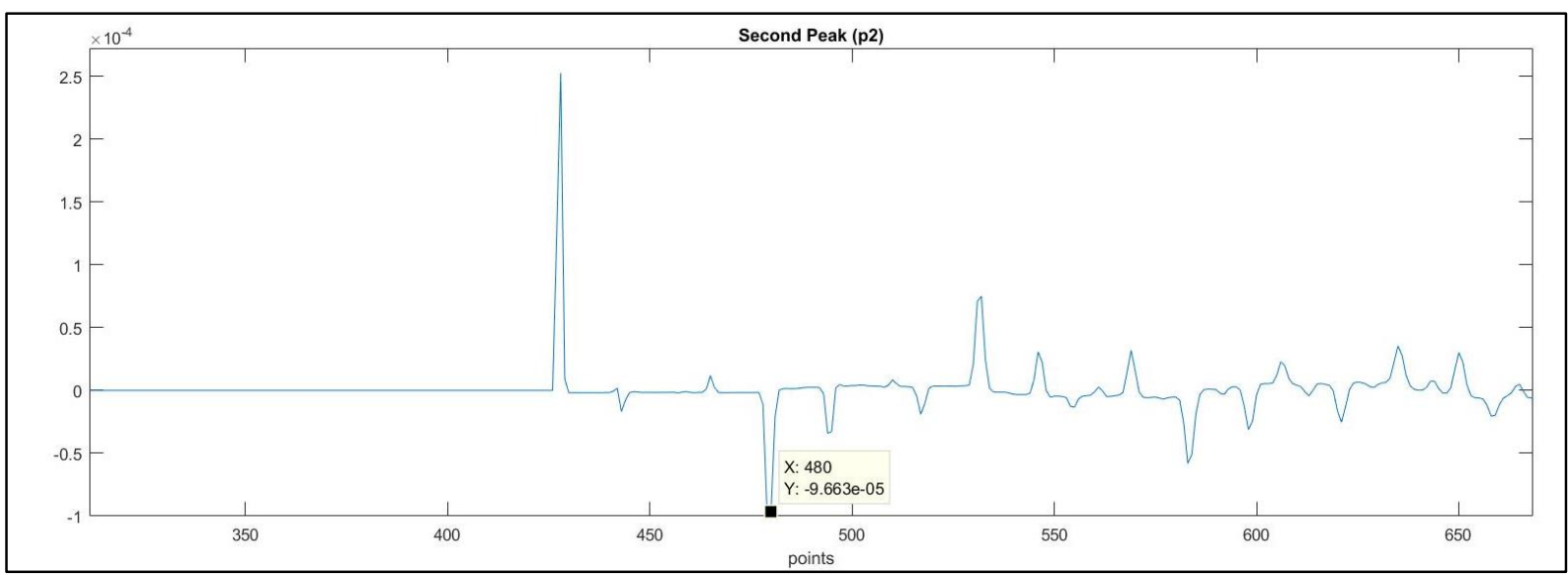

Figure 14. $p_{1}$ and $p_{2}$ and their sample numbers in detail coefficients

The fault distance can be computed as:

$$
m=\left(p_{2}-p_{1}\right) \cdot \frac{v_{\alpha}}{f_{s}}=(480-428) \cdot \frac{289888,7059}{2048000}=7,36 \mathrm{~km}
$$

Since the fault occurred at the tower, the actual location can be obtained by construction list of the line. Actual fault location is 7,31 km from Patnos Substation. The percentage error of the computed location is:

$$
\% \text { Error }_{\text {computed }}=\left|\frac{(7,36-7,31)}{46,587}\right| \cdot 100=0,1 \%
$$

And the percentage error of Distance Relays:

$$
\% \operatorname{Error}_{\text {Relay(Patnos) }}=\left|\frac{(7,31-5,38)}{46,587}\right| \cdot 100=4,14 \%
$$

Maximum error with the Single-End TW Method:

$$
\% \text { Error }_{\text {max }}=\frac{v_{\alpha}}{2 f_{s}} \cdot \frac{100}{\text { line lenght }} \approx 0,15 \% \Rightarrow 70 \text { meters }
$$

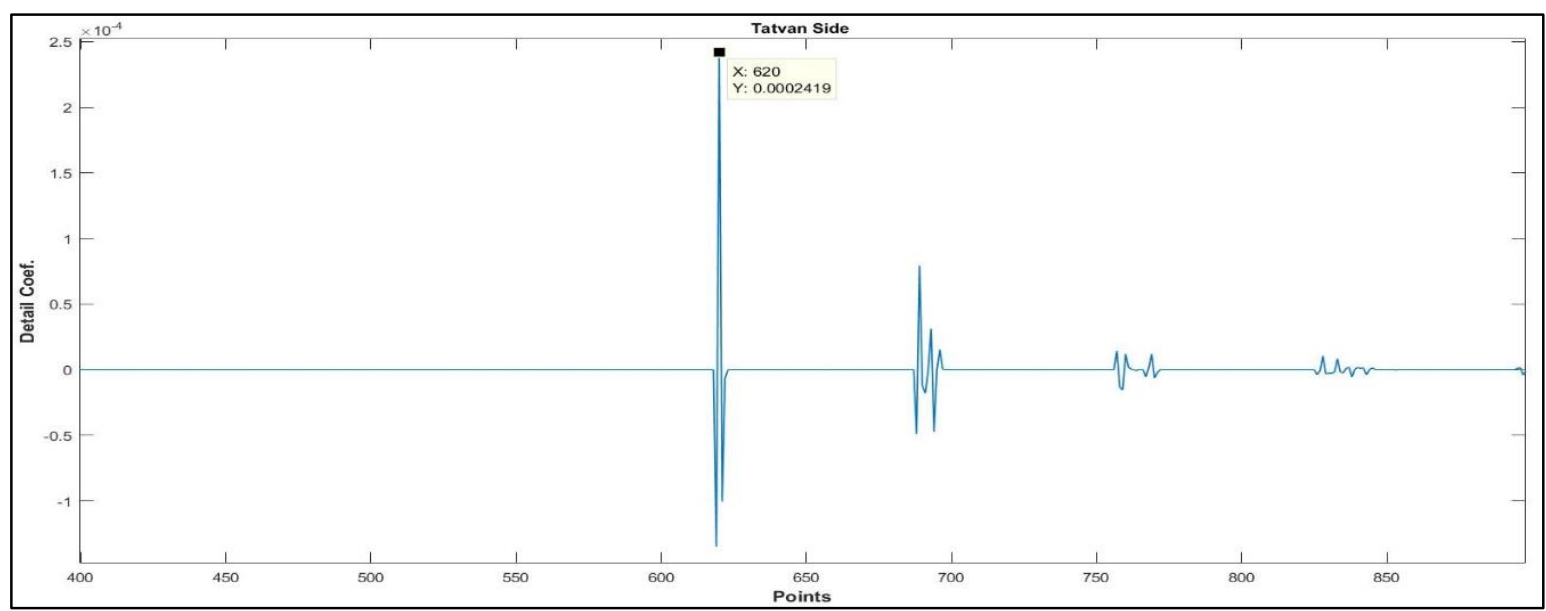

\subsection{Simulation Results of the Fault in $154 \mathrm{kV}$ Tatvan-Mus Line with Single-End Method}

By wavelet transform we can obtain the difference of arrival times of incident TWs. The peaks in Detail Coefficients of first level DWTs represent sudden changes in the signal. The difference of sample numbers of first peaks gives us the difference of arrival times of incident TWs. The fault location expression with $\alpha$-mode velocity for downsampled detail coefficients:

$m=\frac{\ell}{2}+\left(p_{L}-p_{R}\right) \cdot \frac{v_{\alpha}}{f_{s}}$

where $\ell$ is line length, $m$ is fault location, $p_{L}$ is sample number of first peak for the L side signal $p_{R}$ is sample number of first peak for the R side signal $v_{\alpha}$ is wave propagation velocity in $\mathrm{km} / \mathrm{s}$ and $f_{s}$ is sampling rate in Hz. Figure 15 shows first peaks with sample numbers at each side. 


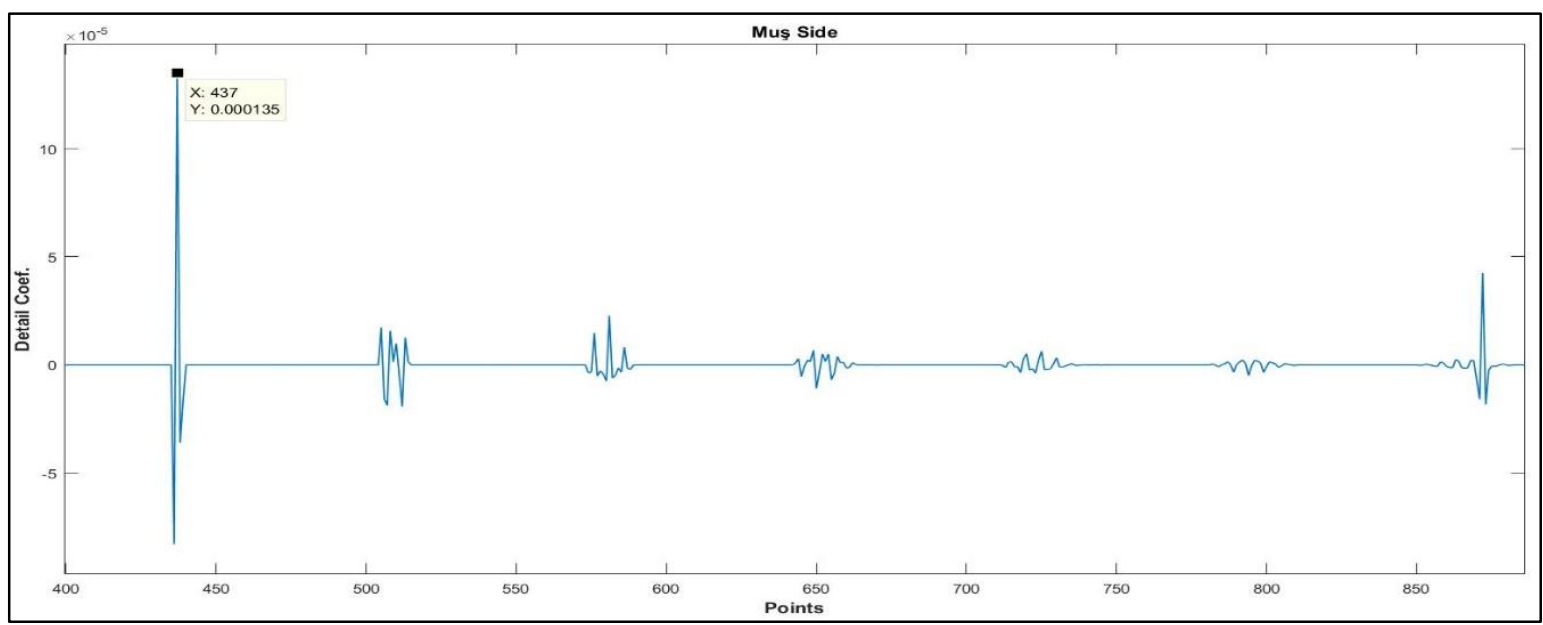

Figure 15. First peaks with sample numbers in detail coefficients

The fault distance can be computed as:

$m=\frac{\ell}{2}+\left(p_{L}-p_{R}\right) \cdot \frac{v_{\alpha}}{f_{s}}=\frac{71,3357}{2}+(620-437) \cdot \frac{289888,7059}{2048000}=$ $61,57 \mathrm{~km}$ from Tatvan

and

$m=\frac{\ell}{2}+\left(p_{L}-p_{R}\right) \cdot \frac{v_{\alpha}}{f_{S}}=\frac{71,3357}{2}+(437-620) \cdot \frac{289888,7059}{2048000}=$ $9,76 \mathrm{~km}$ from Muș.

Since the fault occurred at the tower, the actual location can be obtained by construction list of the line. Actual fault location is $61,52 \mathrm{~km}$ from Tatvan Substation. The percentage error of the computed location is:

$$
\% \text { Error }_{\text {computed }}=\left|\frac{(61,57-61,52)}{71,3357}\right| \cdot 100=0,07 \%
$$

And the percentage error of Distance Relays:

$$
\begin{gathered}
\% \operatorname{Error}_{\text {Relay }(\text { Mus })}=\left|\frac{(10,15-9,76)}{71,3357}\right| \cdot 100=0,54 \% \\
\% \text { Error }_{\text {Relay(Tatvan) }}=\left|\frac{(62,65-61,52)}{71,3357}\right| \cdot 100=1,58 \%
\end{gathered}
$$

Maximum error with Double-End TW Method:

$$
\% \text { Error }_{\text {max }}=\frac{v_{\alpha}}{2 f_{s}} \cdot \frac{100}{\text { line lenght }} \approx 0,1 \% \Rightarrow 70 \text { meters }
$$

\section{Conclusion}

The error of distance relay is 1930 meters with the relay located at Patnos Substation, where the error of simulating same fault with Single-End TW Method is 50 meters. Although Patnos-Erciş HV Transmission line is a short line, 46,587 km, the method has significantly better accuracy than the Distance Relay.

The minimum error of distance relays is 390 meters (relay located at Mus Substation), where the error of simulating same fault with Double-End TW Method is 50 meters. Although, the benefits of the method may not be seen with short lines like
Tatvan-Muș line, it can be seen that the method has a considerable benefit with long lines over $250 \mathrm{~km}$.

It can be concluded by the work that both TW Fault Location Methods are significantly more accurate than the Impedance Based Method.

\section{References}

[1] K. Zimmerman and D. Costello, "Impedance-based fault location experience," 2005 58th Annu. Conf. Prot. Relay Eng., vol. 2005, pp. 211-226, 2005.

[2] P. Jafarian and M. Sanaye-Pasand, "A traveling-wave-based protection technique using wavelet/pca analysis," IEEE Trans. Power Deliv., vol. 25, no. 2, pp. 588-599, 2010.

[3] X. Lin, F. Zhao, G. Wu, Z. Li, and H. Weng, "Universal wavefront positioning correction method on traveling-wave-based fault-location algorithms," IEEE Trans. Power Deliv., vol. 27, no. 3, pp. 1601-1610, 2012.

[4] K. Glik, D. D. Rasolomampionona, and R. Kowalik, "Detection, classification and fault location in HV lines using travelling waves," Prz. Elektrotechniczny, vol. 88, no. 1 A, pp. 269-275, 2012.

[5] N. Fischer, V. Skendzic, R. Moxley, and J. Needs, "Protective relay traveling wave fault location," IET Conf. Publ., vol. 2012, no. 593 CP, pp. 2-4, 2012.

[6] P. Sharma, D. Saini, and A. Saxena, "Fault Detection and Classification in Transmission Line Using Wavelet Transform and ANN," Bull. Electr. Eng. Informatics, vol. 5, no. 3, pp. 20582063, 2016.

[7] V. Siozinys and R. Urniezius, "Transmission line protection and fault location based on travelling wave measurement," Elektron. ir Elektrotechnika, vol. 19, no. 9, pp. 21-24, 2013.

[8] M. Arkan, D. Akmaz, M. S. Mamiş, and M. E. Tağluk, "Design and development of travelling-wave-frequency-based transmission line fault locator using TMS320 DSP," IET Sci. Meas. Technol., vol. 13, no. 4, pp. 491-499, Jan. 2019.

[9] D. Akmaz, M. S. Mamiş, M. Arkan, and M. E. Tağluk, "Transmission line fault location using traveling wave frequencies and extreme learning machine," Electr. Power Syst. Res., vol. 155, pp. 1-7, 2018.

[10] D. Akmaz, M. S. Mamiş, M. Arkan, and M. E. Tagluk, "Fault location determination for transmission lines with different series-compensation levels using transient frequencies," Turkish J. Electr. Eng. Comput. Sci., vol. 25, no. 5, pp. 37643775, 2017.

[11] M. S. Mamiş, M. Arkan, and C. Keleş, "Transmission lines fault location using transient signal spectrum," Int. J. Electr. Power Energy Syst., vol. 53, no. 1, pp. 714-718, Dec. 2013. 
[12] L. Y. Bewley, "Traveling Waves on Transmission Systems," Trans. Am. Inst. Electr. Eng., vol. 50, no. 2, pp. 532-550, 1931.

[13] D. A. Douglass, "Current Transformer Accuracy with Asymmetric and High Frequency Fault Currents," IEEE Power Eng. Rev., vol. PER-1, no. 3, pp. 41-42, 1981.

[14] E. Clarke, Circuit Analysis of A-C Power Systems; Symmetrical and Related Components. Wiley, 1943.
[15] I. Daubechius, "Ten Lectures of Wavelets," Philadelphia, PASosiety Ind. Appl. Math. Anal., pp. 1544-1576, 1992.

[16] M. Baradar, S. Afsharnia, and M. Sanaye-Pasand, "A fast method for fault section identification in series compensated transmission lines," 2010 9th Conf. Environ. Electr. Eng. EEEIC 2010, pp. 483-486, 2010. 